\title{
EDITORIAL SOBRE EL PORVENIR DE LAS REVISTAS JURÍDICAS DE CHILE
}

La pujanza y los desafíos que envuelven el desarrollo de la educación, investigación y praxis del derecho en Chile se vieron en buena medida reflejados en las conferencias, discusiones y recomendaciones que tuvieron lugar en las Jornadas de Reflexión sobre las Revistas Jurídicas que fueron organizadas por la Facultad de Ciencias Jurídicas de la Universidad Católica del Norte, en Coquimbo, en diciembre de 2014. Las jornadas se centraron en torno a las políticas editoriales e innovaciones metodológicas y tecnológicas que promuevan el avance de la comunicación de resultados de investigaciones, de ensayos y otros textos académicos que profesores, investigadores, intelectuales y profesionales de los diferentes campos e instancias del derecho, realizan a través de las revistas editadas nacionalmente e indexadas en SciELO. La importancia de las jornadas se ve reforzada porque estas revistas son responsables de la comunicación de más del $85 \%$ de la literatura jurídica indexada de Chile.

No obstante presentar características propias debido a las áreas temáticas que publican, a legados históricos o el tipo de institucionalidad, las revistas jurídicas chilenas tienen en común su afiliación institucional universitaria y la integración al sistema nacional de educación e investigación en derecho. Se caracterizan también por la operación sin fines de lucro bajo la misión principal de contribuir al avance y diseminación del conocimiento legal. Siguiendo uno de los principios de la Red SciELO, las revistas son publicadas en acceso abierto bajo el concepto de que el conocimiento científico es un bien público.

La pujanza jurídica de Chile se expresa en la amplia presencia nacional e internacional que la literatura jurídica chilena ha alcanzado en la comunicación académica a lo largo de los últimos años. De hecho, Chile ocupa la primera posición entre los países de América Latina en número de artículos y otros tipos de documentos indexados internacionalmente porque ha logrado indexar más revistas jurídicas en los índices SciELO, Scopus y WoS que cualquier otro país de la región. La visibilidad que adviene de esta amplia indexación es intensificada por la publicación online en acceso abierto. Sin embargo, la escritura exclusiva en español persiste como la principal barrera para potenciar la diseminación universal. El uso del idioma inglés enfrenta resistencias casi siempre justificadas bajo la óptica de que la literatura jurídica tiene orientación o interés nacional o regional.

Sin embargo, dos determinantes contradicen esta perspectiva, por lo menos para una parte de la investigación que se comunica: el primero es 
el reconocimiento, hace tiempo ya, que el inglés se ha consolidado como la lengua franca de comunicación de la información y conocimiento científico y, segundo, que la investigación en derecho es esencial para el fortalecimiento de los intereses nacionales y las diferentes interacciones económicas, sociales y culturales en el mundo globalizado. La adopción progresiva y selectiva de la publicación en inglés es un avance esperado para la investigación en ciencias sociales y humanidades de la región y particularmente en derecho.

Otros desafíos, además de la adopción del inglés, fueron abordados desde el punto de vista de la evolución de las políticas, de la gestión y del desempeño editorial. Estos desafíos envuelven tanto cuestiones recurrentes sobre cómo perfeccionar progresivamente la calidad de lo que se publica, como las presiones contemporáneas a favor de la adopción de innovaciones en las formas de comunicación.

La calidad de lo que se publica es un tema que se aplica a todas las revistas independientemente de la disciplina o el área temática que cubren y se correlaciona directamente con el prestigio que adquieren. Por un lado, la calidad es inherente a la relevancia y contribución de las investigaciones e ideas originales que reciben y evalúan los cuerpos editoriales de las revistas, pero, al mismo tiempo, la calidad puede ser más y más potenciada por las funciones de filtraje, evaluación y edición que ejercen los procesos editoriales independientes y transparentes basados en la revisión por pares y obediencia a los preceptos éticos de la comunicación científica. La composición de cuerpos editoriales representativos de la comunidad y con la participación activa de investigadores extranjeros, el seguimiento online del proceso de evaluación de los manuscritos por los autores y editores, y la rapidez del proceso de arbitraje, son algunos de los desafíos destacados relacionados con el mejoramiento de la calidad de las revistas. La superación de estos desafíos demanda por cierto la participación comprometida de la comunidad en sintonía con la gestión editorial que privilegia el profesionalismo, la apertura y expansión internacional de los procesos, cuerpos editoriales y revisores ad hoc.

La otra faceta de los desafíos apunta a la adopción de herramientas y modalidades innovadoras de publicación apoyadas en las tecnologías de información y comunicación que están moldeando la comunicación académica del futuro. Las revistas SciELO han sido pioneras en el uso del medio digital y publicación online en la Web y, por lo tanto, poseen las condiciones para adoptar estas innovaciones. La principal de ellas es la publicación continuada de artículos tan pronto son aprobados y editados, o sea, sin la necesidad de esperar la composición de los números. Esta modalidad de publicación continuada contribuye a acelerar las comunicaciones y promueve, cuando se adopta por las principales revistas de un área temática como es derecho, un flujo dinámico que informa a los estudiantes, investigadores, profesores y profesionales. 
La segunda innovación que las jornadas enfatizaron es la participación activa de las redes sociales como medios de comunicación complementaria a la revista clásica que favorecen tanto el compartir como el diseminar los contenidos entre las comunidades de académicos y de profesionales y el público en general. Para que esta participación sea efectiva se requiere planificación, definición de políticas y procedimientos editoriales, recursos humanos especializados y presupuestos financieros. La participación involucra a los editores, los autores, los lectores y los diferentes medios como son los blogs, los sistemas de colaboración de ideas e información entre investigadores y de gestión de bibliotecas individuales como son Academia.edu, Mendeley, ResearchGate, y los sistemas de comunicación general como son Twitter y Facebook. El desempeño de las revistas y artículos en las redes sociales son acompañados por las llamadas métricas alternativas que complementan los indicadores bibliométricos clásicos basados en las citaciones.

Crear y sostener las condiciones para tener una participación de calidad, eficiente y eficaz en las redes sociales envuelve problemas y soluciones que son comunes para todas las revistas. Un abordaje común y colaborativo, sin renunciar a las agendas de cada revista, se presenta como el camino más viable, apropiado, rápido y económico para ingresar en las redes sociales con el necesario dinamismo y masa crítica de contenidos. Por ejemplo, un blog común de las revistas jurídicas podría convertirse en referencia para la diseminación de los avances en el conocimiento jurídico.

Las jornadas evidenciaron la importancia del diálogo entre los editores en el análisis de las fortalezas y debilidades de sus revistas, de los problemas recurrentes que tienen y de los desafíos que representan las innovaciones en curso en la comunicación científica internacional. El diálogo se mostró especialmente eficaz en la formulación de soluciones. La superación tanto de los desafíos clásicos como de los actuales que fueron abordados en las jornadas apunta, en primer lugar, a la actuación decisiva de los editores y de las instituciones responsables por las revistas, en segundo lugar, a la colaboración entre las revistas y, en tercer lugar, al fortalecimiento de las políticas públicas de apoyo a las revistas científicas editadas nacionalmente como parte esencial del progreso de la investigación científica.

Abel L. PACKer ${ }^{*}$

Coordinador Programa SciELO / FAPESP, Fundación de la Universidad Federal de São Paulo (BRASIL). 